\title{
As ilhas do arquipélago
}

E. M. de M elo e Castro

\section{Onde o mar acaba}

1.

se o mar acaba

o que acontece

\author{
à terra \\ ao ar
}

ao fogo?

se o mar acaba

o que acontece

à água?

2.

onde acaba o mar / começa o ar onde acaba o ar / começa o fogo onde acaba o fogo / começa a terra onde acaba a terra / começa o mar onde começa o mar / começa o ar onde começa o ar / começa o fogo onde começa o fogo / começa a terra onde começa a terra / começo eu onde começo eu / acaba o mar onde acaba o mar / começa o fogo onde começa o fogo / acaba o ar onde acaba o ar / começa o vácuo onde começa o vácuo / acabo eu onde acabo eu / começas tu onde começas tu / acaba o mar onde acaba o mar / vivemos nós

3.

se o mar acaba o espaço se bifurca em siderais paisagens e profundos abismos entre macro galáxias e micro sensações em frágeis borboletas e estranhos atractores onde o caos se revela um outro mar maior povoado de nadas e infinitas cores

onde esse mar acaba / começam as visões E. M. de Melo e Castro 
Um arquipélago é um conjunto de ilhas, o que não quer dizer que algumas ilhas dispersas formem necessariamente um arquipélago. Quando os organizadores deste evento ${ }^{1}$ me convidaram para fazer a sua abertura foi este pensamento que imediatamente invadiu a minha mente. A metáfora diz evidentemente respeito à língua portuguesa e àquilo que com ela fazemos, ou não fazemos, nós seus detentores. Falar de ilhas pressupõe a existência de uma larga quantidade de água, possivelmente um mar ou um oceano, água essa que tanto as une como as isola e separa, formando-se o arquipélago apenas no espaço conceitual de quem o imagina ou vê como entidade coerente e coesa. É tal qual como com as estrelas e as constelações. É tal qual como com a língua portuguesa e os sete países que a detêm e utilizam como seu privilegiado instrumento de comunicação. Cada um constituindo uma ilha e sonhando de maneira diferente com a concepção de um arquipélago em que o Português fosse o tecido que envolve e possibilita a comunicação e não o mar que separa e distancia as falas e os falantes.

É que cada ilha, em si própria, é um micromundo com suas características morfológicas e sua complexidade interna muito próprias e de difícil avaliação. É tanto assim que a medição do perímetro de uma ilha é impossível de efetuar-se rigorosamente seguindo os princípios lineares da Geometria Euclidiana. Só a matemática fractal nos pode dar uma aproximação plausível do valor quantitativo desse perímetro, procedendo por iterações sucessivas. Parece-me que quanto às características culturais e humanísticas de um micromundo, como uma ilha, 
as coisas se passam de igual modo. As avaliações abstratas e lineares de nada nos servirão. Só uma atitude fractal nos levará a aproximarmo-nos das circunstâncias e das razões dos comportamentos dos seus habitantes, como diferenciados dos habitantes até mesmo das outras ilhas que julgamos pertencerem ao mesmo arquipélago. É assim com a língua. É assim com o Português dos sete países que o falam, escrevem e transformam.

Mas no caso de fenômenos culturais e particularmente lingüísticos, o que poderá constituir uma atitude fractal, para lá de mais uma apropriação metafórica de uma concepção científica? Lembremo-nos de que Mandelbrot, o inventor matemático das figuras fractais, chamou desde cedo a atenção para a natureza fractal da natureza e dos fenômenos naturais, tais como a variação da forma e do volume das nuvens, a ondulação da superfície do mar, a agitação das folhas e dos ramos das árvores impelidas pelo vento, as variações climatéricas, o pingar de uma torneira, a turbulência da água fervente, o sistema de ramificações irregularmente simétricas do desenvolvimento dos vegetais, e muitos, muitos outros fenômenos naturais que têm escapado a explicações linearmente racionais. Não é difícil extrapolar para o mundo das ciências humanas e particularmente daquelas atividades a que chamamos lingüísticas como a fala, a escrita, a comunicação, a informação, a criação textual, a invenção do novo poético ou o exercício do raciocínio e da capacidade formuladora do pensamento.

De fato, quem poderá avaliar ou "medir" direta e linearmente as características da fala dos habitantes de uma ilha, ou da capacidade inventiva e transformadora que essa prática lingüística em si comporta diferenciadamente da de falantes de outra ilha da mesma língua? Creio mesmo que a esta luz se impõe a consideração de uma "lingüística F ractal" e que a língua portuguesa, pela sua dispersão em arquipélago pelo mundo, necessita ser estudada à luz de conceitos e normas diferentes das até agora usadas e que não primam pelo brilho dos resultados.

Uma concepção fractal da existência do Português no mundo pode, pelo contrário, levar-nos a conclusões interessantes tais como, por exemplo, a de que o perfil ou "perímetro" lingüístico de cada ilha é uma entidade fragmentada mas única, unidade essa que é constituída por cada vez mais pequenas unidades iterativas, isto é, que se repetem, cada vez mais pequenas até o infinito.

Por seu lado, no caso da língua essas unidades transformadoras iniciam-se no universo microlingüístico do indivíduo falante e escrevente com suas idiossincrasias e transgressões poético-criativas, ou através das práticas lingüísticas de vários grupos sociais, até atingirem iterativamente o nível macrolingüístico de uma nação ou de uma cultura.

A existência portanto de uma norma para todas as ilhas do arquipélago é impossível, porque cada ilha produz as suas próprias unidades iterativas no exer- 
cício das funções lingüísticas que caracterizam e modelam o seu quotidiano falar, escrever, criar e comunicar. Existe uma polivalência lingüística que caracteriza o nosso arquipélago e essa polivalência é não linear mas sim de natureza fractal.

Alguns exemplos são correntes, tais como o uso no Brasil, no registro popular, de formas do particípio passado como pego e escapo em vez de pegado e escapado, ou o uso da crase 'à' apenas por razões fônicas, ou a utilização de verbos duma forma metafórica, ou a não concordância entre plural e singular. Tais procedimentos, longe de serem apenas meras fugas à Norma, são, isso sim, manifestações da natureza fractal da nossa língua, que por iteração se repetem desde o nível microlingüístico até o macrolingüístico, tornando-se prática aceite e por isso caracterizadora e diferencial.

Também a intensa e quase espontânea formação de neologismos é disso um sinal, o mesmo se passando com a adoção de radicais de línguas indígenas como por exemplo o sufixo tupi "rana" que tem o sentido de "como se" e exerce uma função modalizante de substantivos. Um exemplo erudito desse fenômeno é o título de uma bem conhecida obra de Guimarães R osa: "Sagarana", isto é, "como se fosse uma saga".

Também no registro erudito é oportuno lembrar a carta de G uimarães R osa a J oão Condé em que o primeiro confidencia: “M as ainda haverá mais, se possível (...) além dos estados líquido e sólido, porque não tentar trabalhar a língua também em estado gasoso?". Ora, o estado gasoso possui uma enorme entropia e é caracteristicamente fractal e caótico.

O estado gasoso de uma língua será portanto aquele em que a invenção e o novo atingem o seu maior grau de probabilidade.

É o que acontece nos países africanos de Língua Portuguesa, notavelmente em Angola, em que a literatura, a partir principalmente de Luandino Vieira, cria verdadeiras fraturas ao introduzir no discurso vocábulos, lexemas e até fragmentos discursivos de dialetos e línguas africanas, evidenciando uma concepção interlingüística e intertextual que transforma o português num fractal polilingüístico com uma extraordinária energia de expansão iterativa capaz de fundar uma literatura e estruturar uma nova cultura.

Também um forte sentido de criação onomatopaica motiva e invade uma boa parte da poesia africana de expressão portuguesa, como por exemplo no poema de Marcelo da Veiga, da Ilha do Príncipe:

Que cheiro o da mangueira,

Que cheiro!...

Sol foi-se, a noite cai... 
O xapo-xapo cheira,

Mas o morcego sai

Direito ao mamoeiro:

"Kié... K ié..."

"B u-bu-bu-bu-bu-bu..."

J á virou, já caiu

No xapo-xapo ao pé,

$\mathrm{Na}$ banana ou limão.

O garotio

Em desafio,

Toma a funda e... zás!

Fugiu pra a fruta-pão:

“Bu-bu-bu-bu-bu-bu”,

Insaciável, voraz.

Fechou-se a noite toda.

Ao pé,

E à roda,

No canto em que se acoite,

Cada um a dormir caiu,

Só ele: “Kié... kié... kié... kié..."

"Bu-bu-bu-bu-bu-bu" -

Toda a noite...

Neste poema as sinestesias entre cheiro e gosto das frutas é suportada por uma intencional fragmentação do discurso e pela qualidade fônica das associações vocabulares e onomatopaicas.

No Portugal continental e ibérico alguns fenômenos de natureza fractal se vêm observando nos últimos anos, contrariando e fraturando os hábitos lingüísticos de uma suposta norma. R efiro-me ao uso pela imprensa, na construção de títulos mais ou menos sensacionalistas, de práticas textuais com origem na Poesia Experimental dos anos 60, tais como as transformações parafonéticas de vocábulos e frases, ou as aproximações improváveis de lexemas, ou as transformações morfo-semânticas por associação ou dissociação e fragmentação de vocábulos, processos esses que originam verdadeiras catástrofes fractais na comunicação social mas que possuem uma enorme capacidade de iteração macrolingüística, estando realmente a transformar os hábitos lingüísticos dos leitores. Um outro fato disruptivo é a influência das televisões espanholas ao longo da fronteira, provocando um novo bilingüismo e contribuindo para o apagamento dessas mesmas fronteiras em termos de língua falada. 
Tais procedimentos fractais relevam do aumento da entropia lingüística, fato que se torna muito evidente no Brasil em que estatisticamente os fatos sociolingüísticos atingem dimensões mais salientes e ativas do que nas outras ilhas do nosso arquipélago. Por isso creio que ao Brasil caberá um papel de relevo na manutenção da língua portuguesa no universo da comunicação global em que já atualmente vivemos.

Contraditoriamente, dada a enorme turbulência sociolingüística que se observa, o Brasil é do nosso arquipélago a ilha mais sensível e permeável aos distúrbios causados pela globalização da informação numa língua diferente do Português, como é o caso do inglês e talvez ainda mais num linguajar informatizado que se serve dum inglês primário e distorcido.

Por outro lado a desmaterialização dos suportes lingüísticos pesados, ou seja o papel, o livro, a revista ou o jornal, que se realiza através das imagens virtuais e do hipertexto, acompanhada da comunicação em tempo real (como na Internet) cria a ilusão da realização da utopia do entendimento e da comunicação universal sem os inconvenientes das especificidades lingüísticas e culturais dos participantes dessa mesma comunicação. Nesse paraíso virtual da linguagem, onde ficam as línguas? No nosso caso, onde fica o Português?

Paul Virilio vem apontando para a não inocência da cibernetização dos meios de comunicação e chega a falar no totalitarismo da colônia global multimediática, e para os perigos de um possível "golpe de E stado informacional" que, através da impunidade dos jogos de guerra informáticos e pelo branqueamento virtual da informação produzido pela Internet, nos cria a ilusão de que um "software democrático" nos está levando sem custo e sem dor para o universalismo lingüístico. Mas onde ficam as línguas, e onde fica o Português? Ao repetir esta pergunta creio que me autodenuncio como ignorante da resposta.

Fernando Pessoa, esse grande produtor de teorias e de utopias imaginou a virtualização de Portugal, não mais como um suporte geográfico mas sim como um suporte desmaterial lingüístico, transformando-o na Língua Portuguesa. No mesmo passe de mágica Portugal se transformaria numa "sociedade secreta chamada Portugal" que estaria onde estiver um falante ou um estudioso do Português.

Gostaria de acreditar que essa seria ou será uma das soluções possíveis introduzindo fractalmente o português em fissuras e pontos fracos que existem sempre em todos os sistemas totalitários, sejam eles atuais ou virtuais.

$\mathrm{N}$ ão seria isso mais do que estender o sistema da mestiçagem até ao nível universal da comunicação interativa. M estiçagem que sendo um processo barroco bem conhecido nas ilhas do nosso arquipélago, ultrapassa a soma das memórias dos participantes produzindo um saber lingüístico geneticamente incontrolável, resultando em bifurcações imprevisíveis e em figuras de caos a que 
se dá o nome científico de "atratores estranhos" mas a que nós poderemos chamar provavelmente de "criações poéticas" dum futuro que já começou.

É portanto pela prática do português oral e escrito e pela sua capacidade já provada por séculos de criatividade poética, de provocar transgressões e fraturas no tecido comunicativo, que devemos entrar no jogo da virtualidade global. É persistindo no uso do Português como língua de inventar Poesia que devemos entrar no próximo século e milênio, procurando desenvolver a capacidade tecnológica necessária para encontrar o novo lugar das ilhas do nosso arquipélago lingüístico separadas e unidas pelo novo mar cibernético da energia luminosa de que se fazem as imagens virtuais. Mas tenho a certeza também que é persistindo no estudo cada vez mais sofisticado da língua e das literaturas produzidas em Português, nos seus diferentes modos e pendores, e principalmente sublinhando as diferenças que dialeticamente nos unem, que chegaremos um dia a ter algumas respostas.

O simples fato de estarmos aqui reunidos neste dia confirma o otimismo de que talvez possa ser acusado ao acreditar, como o faz Pierre Lévy, que desmateriali zação e hominização serão os agentes dialéticos do drama lingüístico do próximo século.

Termino, tal como comecei, com um Poema, este publicado há poucos dias na Folha de S.Paulo. Penso que vem a propósito:

Criar meu web site

Fazer minha home page

Com quantos gigabytes

Se faz uma jangada

Um barco que veleja

Que veleje nesse infomar

Que aproveite a vazante da infomaré

Que leve um oriki do meu velho orixá

Ao porto de um disquete de um micro em Taipé

U m barco que veleje nesse infomar

Que aproveite a vazante da infomaré

Que leve meu e-mail até Calcutá

Depois de um hot link

Num site de Helsinque

Para abastecer

Eu quero entrar na rede

Promover um debate

J untar via Internet 
Um grupo de tietes de Connecticut

De Connecticut acessar

O chefe da Macmilícia de Milão

Um hacker mafioso acaba de soltar

Um vírus pra atacar programas no J apão

Eu quero entrar na rede pra contactar

Os lares do Nepal, os bares do Gabão

Que o chefe da polícia carioca avisa pelo celular

Que lá na praça Onze tem um video pôquer para se jogar

"Pela Internet", composta

por Gilberto Gil neste ano

(inédita)

\section{Referências bibliográficas}

ANT OLOGIA. Onde o mar acaba. Lisboa: PEN Clube Português, 1992.

FERREIRA, Manuel (org.) 50 poetas africanos. Lisboa: Plátano, 1989.

LÉVY, P. O que é o virtual?. Trad.: Paulo Neves. Rio de J aneiro: E ditora 34, 1996.

MANDELBROT, B. The fractal geometry of nature. San Francisco: F reeman, 1982.

MELO E CASTRO, E. M. de. Poética dos meios e arte hightech. Lisboa: Vega, 1988.

ORLANDI, E. P. \& SOUSA, T. E. C. de. Política lingüística na América Latina (A língua imaginária e a Língua fluida: dois métodos de trabalho com a linguagem). Campinas: Pontes, 1988.

THEODORO, J. América barroca. Rio de J aneiro/São Paulo: Nova Fronteira/E dusp, 1992.

VIRILIO, P. A arte do motor. Trad.: Paulo Roberto Pires. São Paulo: Estação Liberdade, 1996. 